\title{
Queer at Camp: The Impact of Summer Camps on LGBTQ Campers in the United States ${ }^{1}$
}

\section{Penny Harvey, Juhwan Seo, Emily Logan}

\begin{abstract}
The purpose of this study is to explore the ways in which LGBTQ campers and counsellors are shaped by and shape summer camp. Summer camps are often the place where many US youth begin to learn about sex and sexuality. It is a unique and important spatial locale that is understudied in both sexualities and wider sociological enquiry. To better understand the impact of summer camp experiences on sexualities, the study analyses retrospective interviews with former campers about their experiences at a summer camp, as well as podcasts and blogs. We address two key areas of camp life: sexual firsts and being openly queer at camp. Many campers are less likely to be out at camp than they are at home. The exception to this is when there are visible staff or counsellors that are out at camp. Despite not being out, many LGBTQ campers have their first sexual experience at camp, though many do not see it as sexual at the time of the act. Our findings reaffirm the importance of contact with queer people, both for LGBTQ acceptance from straight/cis people and for the self-acceptance of young queer persons. We conclude by discussing how this space is unique and how it can be improved for LGBTQ people's experiences and development at summer camps.
\end{abstract}

Keywords: summer camp, LGBTQ, total institution, coming out

Harvey, Penny, Seo, Juhwan, Logan, Emily. 2021. Queer at Camp: The Impact of Summer Camps on LGBTQ Campers in the United States. Gender a výzkum / Gender and Research 22 (2): 45-70, http://dx.doi.org/10.13060/gav.2021.019.

Every summer in the United States, 11 million children pack their bags and head off to summer camp (American Camp Association Camp Compensation and Benefits Report 2010). At camp, there are no parents or adults (except those in the role of camp counsellors), and home often seems a million miles away. It is a cultural

\footnotetext{
1 Acknowledgements: We would like to acknowledge all our colleagues and peers who read and provided comments on this article in the draft stages. We would also like to thank our participants for sharing their stories with us.
} 


\section{NV STATI / ARTICLES}

haven, a place where anything can happen. Summer camps have been a staple of US culture for decades. From their inception in the early 1880s, the design and purpose of summer camps have changed. Some camps have remained as 'back to nature' retreats, whereas others have focused on modern specialties like robotics and space. Regardless of their purpose, summer camps have become one of the most influential institutions on youth in US culture (Van Sylck 2006).

This article considers how summer camp can have a transformative impact on how teenagers come to terms with their (queer) sexuality. Summer camps are often where many US youth begin to learn about sex and sexuality (Van Slyck 2006). Camp is a unique social context that detaches youth from the all-consuming institutions in which they are raised, namely families, neighbourhoods, and schools, which may restrict and dictate normative gender and sexual behaviour. Despite being a unique locale that serves as a crucial site for the development of sexuality for youth, summer camps have been largely overlooked in the literature on how children explore their sexuality and come in contact with queer adults.

We address two areas of camp life - sexual firsts and being openly queer at camp - by analysing in-depth interviews with 10 former campers, as well as 18 media sources including podcast episodes, blog posts, and the comments sections of the media sources, about people's experiences at camp. For both first sexual experiences and being openly queer, summer camp serves as a meaningfully different context compared to life outside of camp - in the 'real world'. We highlight how camp becomes an environment for most campers' first sexual experience - both straight and non-straight experiences. There is a discursive myth-making that camp is a heteronormative space; however, when examining behaviours and actions, nonheterosexual acts take place more frequently than many assume. On the outside, camp appears heteronormative - the rituals and structures certainly are - but behind closed doors campers engage in behaviours that are, for some, same-gender sexual experiences. Campers are less likely to be out at camp than they are at home, and straight campers, despite knowing people who are out in their age groups at home, assume everyone at camp to be straight. The only occurrences of campers being any degree of out at camp is when there are camp staff or counsellors who are out at camp. In this article we question how camp culture is different from the 'real world' and what it is about camp that causes these differences. We find that the routines and rituals of camp, which are considerably gender-segregated, explicitly normalise and centre the visibility of heterosexual couples and genders as oppositional. This causes queer campers to view camp not as a 'safe' place to be out. However, when there is greater visibility of LGBTQ counsellors, the acceptance of LGBTQ campers among other campers also improves. These effects are also reflected in gender nonconforming campers' experiences, which are not addressed in full in this article but 
are covered elsewhere (Harvey 2017). Our findings reaffirm the importance of contact with queer people, not only for LGBTQ acceptance by straight and cis people, but also for self-acceptance among queer youth. Moreover, we advocate for the queering of summer camps, or at least the decentring of heteronormativity, through the rebuilding of camp structures and rituals.

\section{Literature review}

\section{Total institutions}

We argue that summer camp is a total institution, a place that is remote and removed from the rest of society, with a structured schedule and set of rules, and limited contact with the outside world. Goffman (1968) defines a total institution as 'a place of residence and work where a large number of like-situated individuals, cut off from wider society for an appreciable period, together lead an enclosed, formally administered round of life' (xxi). Goffman's concept of total institutions is usually applied to involuntary institutions such as prisons; however, the total institution framework can also be applied to more voluntary institutions such as boarding schools or monasteries. Summer camps fit best into Goffman's (1968) 'retreats from the world' group, the category in which he includes monasteries (Davies 1989; Bargiela-Chiappini 2007; Vrooman 2007; Cookson, Persell 1985; Khan 2012). From our findings, we can confirm that in this unique locale meanings are reconstructed so that camp is then more than a vacation activity and could have implications for young people's development. In fact, as we discuss below, respondents often contrasted camps with 'real life', clearly demonstrating the unique meanings assigned to camps by former campers.

Goffman (1968) argues that those who exist in total institutions commonly face the challenge of complying with the organisation's expectations while simultaneously maintaining a sense of self. For adolescents, then, the institutional norms, boundaries, rules, and rituals of summer camp coincide with the life-course phase of adolescence to create a bubble that is free from the long-lived social consequences of 'real life' (Nenga, Baccam 2010). Total institutions provide a space in which to renegotiate cultures, as well as to renegotiate the self; however, they are also very influential in setting cultural norms and expectations and in shaping a person through collective socialisation. Research on the development and embodiment of gender norms in total institutions, including the military (Pershing 2006) and fire stations (McDowell 2001), has highlighted the role that these institutions play in shaping sexual identity and behaviour, though few have considered how these processes work among youth. Therefore, total institutions provide a useful framework for understanding the development of youth sexualities at summer camp. 


\section{Queerness and space}

The nature of a total institution shapes the space in which the summer camp and the culture within it exist. Gray (2009) argues that queerness is relative to space. By shifting space and geographies, sexuality can be read differently. For example, wearing flannel and jeans as a woman may scream dyke in New York City, but in the Midwest, such gender presentation would be considered normative and the woman's sexuality would be left unquestioned; by common standards women dressed this way may not be considered butch at all (Gray 2009; Kazyak 2012; Brown-Saracino 2015). Place and social context can heavily shape how sexualities are not only read, but how they are enacted (Brown-Saracino 2015).

Similarly, at summer camp, girls are more likely to get down and dirty - playing in the mud, building fires, dealing with bugs - whereas boys are expected to have camp spirit, play dress up, and cry on nostalgia night (a night when everyone watches clips of the summer). The space of summer camp makes it easy to hide in plain sight; traditional ways of flagging might not be read as LGBTQ in these spaces. Moreover, the pressure to fit in, from returning counsellors and campers alike, can further push campers to assimilate, leading to the erasure of queer space and identity (Ghaziani 2015).

At the time of data collection, the research on experiences of LGBTQ youth at summer camps was limited (Oakleaf 2010). However, the field is growing and new research emerging (see Gilard, Buzuvis, Bialeschki. 2014; Browne, Gillard, Garst 2019; Kidd et al. 2019; Baker, Hannant-Minchel 2020). What these studies show is that the institution of camp and its unique cultures and norms have a great impact on the development and selfhood of LGBTQ youth (Kidd et al. 2020). When done well, camp can have unmatchable positive effects on self-esteem, belonging, and growth into adulthood (Gilard et al. 2014; Browne et al. 2019; Kidd et al. 2019). However, when institutions ritualise heteronormativity as the only option, the effects can be deeply problematic (Oakleaf 2010; Harvey 2017; Kidd 2019)

In part because of the nature of total institutions and because summer camp is a unique locale, the formation of sexuality (particularly among youth) is complex in this space. It is important to understand how much space can shape not only queer visibility but also a person's ability to display their queer sexuality. Moreover, by considering camp a unique space, we can explore how the development of sexuality among youth can vary in everyday spaces and unique spaces.

\section{Contact hypothesis}

Contact with and the visibility of LGBTQ people is important both for the acceptance of LGBTQ people and for self-acceptance among youth. We address how summer camp was still able to give campers a great experience without LGBTQ acceptance, but how these benefits were amplified when LGBTQ acceptance was also in play. 
Most of the work done on the contact hypothesis centres on the work done by Allport (1954 in Pettigrew, Tropp 2005), whose theory suggests that contact with an 'othered' group reduces stigma and prejudice associated with this group. Since the 1950s, when this theory gained recognition, countless studies have been done to address the empirical and testable value of this theory for the LGBTQ community (Herek, Glunt 1993; Gaines, Garand 2010; Scheibe, Barrett 2017). To utilise this theory, we must understand the details of its function. Recent research on this theory has shown that the type of contact - beyond simply the contact itself - matters. The relation of the contact, the view of the ego before contact, the frequency of contact, and the identity of the person all matter but have different effects (Herek, Glunt 1993; Costa, Pereira, Leal 2015; Cox, Bimbi, Parsons 2013; Garner 2013). Therefore, having an LGBTQ-identified counsellor could have similar effects on self-acceptance and identity development among LGBTQ youth at summer camp, and the uniquely isolated setting of a summer camp will help us identify the factors that mediate the benefits of minority contact for self-acceptance.

\section{Coming out, acting on desires}

The visibility of LGBTQ counsellors can shape campers' self-acceptance. When do youth, or young adults, realise they are 'not straight'? How much time is there between this realisation and 'coming out'? Of course, coming out is a continual process, and not something that happens just once (Rhoads 1994; Horowitz, Newcomb 2002). People often explore and act on desires before, during, and after the coming out process (Kar, Choudhury, Singh 2015; Peterson 2015). Horowitz and Newcomb (2006) argue that there is no end to the development of a non-straight identity, that over a lifetime an identity continues to grow, shift, and develop. As the choice to come out must be made repeatedly in different spaces and locales, what influences someone's choice to come out? What makes a space safe? What influences someone's choice to come out for the first time? It has long been documented that coming out is a process that has several developmental stages (Coleman 1982). Though these stages are not always linear, they have been categorised as: consciousness, exploration, first relationships, integration/identity development, and disclosure (Coleman 1982).

Consciousness is where a person first acknowledges same-gender desire, which often takes place during the teenage years, though it is commonly later for bisexual individuals (Coleman 1985; Julian, Duys, Wood 2014). Exploration follows consciousness, though there is often a developmental lag in same-gender exploration (Grace 1979). Note that both consciousness and exploration take place in age range when many young people attend summer camp, making camp the unique space where the coming-out process often begins. It is also important to note that samegender exploration or sexual activities do not always lead to a person adopting 
a queer identity (Kinsey 1949; Horowitz, Newcomb 2002; Ward 2008). Later come first relationships, integration, and disclosure, though this process is not linear and does not follow the same pattern for everyone. The decision to disclose is often linked to when these stages occur. Perhaps importantly for summer camps, disclosure is less likely because it is a process that needs social support, and tight-knit (supportive) communities. This is because social support is essential in the disclosure process (Griffith, Hebl 2002; Ragins, Singh, Cornwell 2007). Support is usually built into high school structures, either by students via gay-straight/gender sexuality alliances (GSA), or through more formal support by the institution. At summer camps these programmes and structures are absent. Therefore, the availability of social support is structurally determined by these spaces, influencing the likelihood of coming out.

\section{The current study}

This study draws on the literature of total institutions, queer geographies, and the contact hypothesis to explore summer camps as a voluntary total institution. We investigate the impact of camp culture, structures, and communities on youth sexuality and sexual experiences. To this end, three research questions are addressed:

1. How is the institution of summer camp shaped by heteronormative influences and what effect does that have on LGBTQ campers?

2. Do LGBTQ campers have sexual firsts that mirror those of their straight/cis counterparts? How are these reconciled in the context of both the institution and their identity formation? How does camp as a unique space matter for how people, particularly youth, make sense of their sexuality?

3. Are there any out campers or counsellors in these spaces? How does their visibility or lack of visibility shape the culture and rituals of the environment?

\section{Methods}

Studying children's experiences at summer camp can be troublesome as access to youth is often limited. Therefore, this article focuses on the interpretation of two data sets: in-depth interviews and online archives. The interview data come from a case study of a summer camp in the north-eastern United States, in which four women and six men, all of whom were former campers, were interviewed. The online archive consists of blogs, articles, and podcasts that address the experiences of queer people who have attended or worked at summer camps. Participants were recruited using a snowball sampling method that targeted adults who had attended the same camp within a five-year period. At the time of the interviews, all the participants had attended the camp within the past five years and attended at least five times. They spent a combined 4,067 days at camp (almost 11 years in total) and an average of 8.2 
summer sessions each. In total, the sample represents around 150 to 200 former campers. They were selected because they had all recently attended camp, but they were now over the age of 18 and were no longer attending camp as a camper. We used a case study design for the interviews to get richer data, with comparisons on events that happened in the same place over the same time period. By having our interview participants recount their perception of their experiences at the same institutions, we control for distinct differences in the institutions. By combining this with data from blogs and social media, we can determine whether the findings we had in our original dataset are reflective of a wider camp experience.

\section{Data}

All the interviews were conducted over video teleconferencing and ranged from 45 minutes to 2 hours in length. The interviews were semi-structured and contained questions that covered three primary areas: the overall camp experience, gender at camp compared to at home, and sexuality at camp compared to at home. This paper will focus on data primarily derived from the responses to the questions in the third category. All the interviews were audio-recorded and transcribed.

Following the interviews, a content analysis of nine blogs, three podcasts, and four articles was conducted. Media were chosen according to the following criteria: the author now identifies as LGBTQ and the author attended camp as a camper or counsellor. We primarily searched for media on Google, Tumblr, and podcast hosting platforms such as Apple Podcasts, Spotify, and SoundCloud. The online search was conducted using the keywords 'lesbian', 'gay', 'queer', 'trans', 'homosexual', 'summer camp', and 'camp'. Though our data do not offer a representative account of all summer camp experiences, our aim is not to make general claims about the vast experiences of summer camps. Instead, we are interested in exploring the ways in which LGBTQ former campers and staff understand their summer camp experiences, how they felt as LGBTQ campers and staff, and the meaning of summer camp attendance, and its effect on campers' and their peers' sexuality and gender. Therefore, the unique contrast of the in-depth data from the case study interviews and wider online sources provides a unique insight into this usually closed-off social context.

We also chose to include comments left on each media piece as part of our data. By doing this, we decentre the voices of those who have the cultural and economic resources to create this content and gain a wide audience. Moreover, we argue that this strengthens our data, as we found where the experiences of those who produced the media were reflected or rejected in the comments, therefore showing where specific experiences coincide and differ across a broad range of camps. By supplementing interviews with media in these forms, we strengthen the claims we can make about the queer summer camp experience. 


\section{NV STATI / ARTICLES}

\section{Analysis}

A thematic analysis was conducted first on the interviews and then on the media texts. We followed the structure outlined by Braun and Clarke (2006). We began, however, with the interview transcripts. The first author did the first round of transcription and then the initial generation of codes. The authors then organised the codes into overarching themes relating to the research questions on sexuality-based experiences. The transcripts were then read two more times to catch any other data relating to the themes that were not caught in the initial rounds of coding. The first author's positionality is that of an 'insider': they worked in the summer camp industry and conducted the interviews. Therefore, once the second set of data were collected by the third author, who is an outsider to the summer camp experience, the first two authors also did a secondary read of the transcript data following the above process, both to test intercoder reliability and to see if any additional themes emerged. Then both the first and the third author read the media data to look for data that fit the themes identified in the interviews, and to review it for any additional emergent themes. We found that the two (insider and outsider) perspectives provided the benefits of both a view from the inside, which enabled cultural understanding and context, and a fresh set of eyes with which to look at the whole summer camp cultural experience. Through this process, we carried out repeated close readings of the blog texts, comments, article texts, podcast transcripts, and transcripts of the interviews to identify common themes. The themes were reworked and refined in consultation with each other, and then a final round of analysis of both data sets was conducted using the final set of themes and codes from both sets of data. Where there were discrepancies, we talked through the intention and understanding of a certain code and came to a mutually agreed upon solution. We ended up with three broad themes relating to sexuality at the summer camp: the camp as a heteronormative institution, sexual firsts, and being out at camp.

\section{Findings}

We find that camp is a unique place in terms of how former campers and counsellors construct it as simultaneously safe and not safe. For some, camp was a place where they experienced their sexual first despite the heteronormative practices around them. Some of the same-gender sexual firsts even occurred in plain sight, though they occurred under the guise of 'practising' heterosexuality or demonstrating how straight they were (thus homoerotic acts were not to be to read as 'gay'). For others, camp was a place where they hid a large part of themselves, fearing others would see through their cover. However, some campers also had the experience of witnessing, some for the first time, 'out' role models, especially those not facing persecution. Such initial contact proved to be an immensely powerful experience, showing the validity of the 
contact hypothesis. Nonetheless, these experiences did not occur in isolation; most former campers and counsellors alike had a mix of these experiences, which suggests that camp is neither a perfectly affirming nor a wholly exclusionary space. We begin by explaining how such contradictions come to be, and how camp shapes the sexual identity and experiences of campers. We then examine the sexual firsts of campers and how and if the straight and not-so-straight sexual firsts mirror one another. Finally, we address the impact of outness at camp and how possible it is to be out.

\section{Camp as a heteronormative institution}

Camp is a total institution, one that reflects the heteronormative values, norms, and ideals of the broader society. Despite instances of queer sexual firsts and out counsellors, we found that there is a strong heteronormative nature to camp as an institution. The influence that camp has on youth's development is undeniable. Former campers addressed the consequences of the institution's norms and practices extensively in their interviews:

Jack: The relations between guys and girls, it was very heteronormative.

Aaron: It was almost this prescribed thing, everyone had a boy or girl for the summer, and it was this weird thing where you almost had to have that.

Kayla: You sit outside the canteen and there is a group of guys and a group of girls, and that structure promotes it.

Regardless of whether it was part of the culture of a camp or its structural organisation, it was assumed, especially once the campers were teenagers, that the boys and girls would (want to) pair off. The cultural norms of summer camps, aided by their structured activities, promote the heterosexual pairing of the campers. This pattern was replicated in the stories we found in the blogs, articles, and podcasts.

Blog: The most notable challenge for campers and counsellors who are trans in particular is that living spaces and some bathroom and shower spaces are still gender-specific.

Blog: By my last few years at camp, it had become clear that one of the things that marked me as a weirdo was liking girls.

As shown by these quotes, the assumed heteronormative nature was not just an issue for non-straight teenagers but also for trans and gender non-conforming campers. The extent to which an institution was heteronormative or explicitly regulated heterosexuality was influenced by their affiliation. The more religious (usually Christian) camps promoted the idea that choosing to be gay was against 


\section{NV STATI / ARTICLES}

God or that Christian love was between men and women. In other camps, there was no explicit condemnation of same-gender relationships, though it was implied that only heterosexuality would be expected and accepted. There were rare instances of campers finding camp to be a queer affirming place, as the quotes below reveal, but most camps were not found to be like this. On 26-year-old queer/dyke wrote:

Article: When I tell people about my camp experience, they're surprised that such a climate could flourish within a quintessentially all-American institution an institution for American children, no less, who must be protected from just about everything

This sentiment was echoed by another queer, trans blog poster:

Blog: There wasn't a moment that passed all summer where I felt uncomfortable about my gender or queer identity with another staff member.

At most camps, queer identity was used to diminish the status of camp counsellors, another clear indication of the heteronormative nature of camps. In both interviews and online data, we found instances of gay men counsellors being assigned to overseeing younger boys as a way to keep them away from the teenagers.

Blog: I was in a tent with the youngest boys.

Jacob: One summer there were like 15 gay guys, they were all put on lower camp, I guess to keep them away from the teenagers and the way they would be treated up there.

Having the non-straight, non-cis counsellors only oversee the younger children shows that LGBTQ counsellors were not seen as equal to other counsellors. The implication is that gay counsellors pose a threat to adolescents. Driven by the 'gay panic', camps systematically relegated queer counsellors to lower status positions. The devaluing of queer counsellors alienates campers, who may then be regarded as deviant in terms of their gender or sexual performance. An avid dancer, Ashley recalled having his sexuality questioned because of his enthusiasm for dance and decided that it would be better not to return to camp than risk being treated as a social pariah. These institutional norms made it clear to both counsellors and campers that camp is not a safe space for non-normative gender and sexuality.

Despite the structure of the institution being overly heteronormative, we also came across several examples indicating that there were plenty of implicit sexual rituals at camp. 
Blog: We found an entire tent of nine-year-olds' hiding under a blanket, naked together.

Blog: The enforced mass skinny dipping? The constantly drunk, hypersexual male counsellors? The collective disdain for the 'sister camp'? The communal showers? The skimpy uniforms? 'Shirts and Skins'?? ARTS AND CRAFTS! Oh God, we never had a chance.

In our case study, several of the campers discussed an event called 'sausage fest'. Sausage fest is an event for teenage boys that is full of innuendo and campsanctioned, sexualised horseplay. Events like these make a joke out of homosexuality and centre heterosexuality as the 'real' and 'authentic' attraction. Previous research on summer camps has shown how camps sanction and organise events that not only ridicule homosexuality but also actively try to delegitimise it (Harvey 2017). Events like this show why people were afraid that they would be ridiculed if they disclosed their non-straight sexuality, as the camp itself supported events that made fun of acts that were supposed to imitate/resemble homosexual activities. We see this parallel in other research on total institutions that engage in rituals of homonormativity, ranging from sports, to boarding schools and the military (Schaverien 2004; Eng 2008; Flood 2008; Wadham 2013). Despite camp's unique culture, given its status as a total institution, many camps often reflect the heteronormative influences of wider society. Campers and counsellors alike are then constrained by these norms. However, the silver lining here is that camps are perhaps a locale where we could see major changes in pervasive heteronormativity. As total institutions, camps function autonomously and are beholden to few structural constraints, making them ripe spaces for institutional and cultural change. Therefore, they could quickly become a more accepting environment for sexuality development across a diversity of sexual identities.

\section{There's a first time for everything}

Summer camps are often the place where US youth begin to learn about sex and sexuality (Van Slyck 2006). Camp is often where campers may have their first sexual interaction or experience, experiences ranging from the first time they ask someone to prom to the first time they have sex. Aaron, for example, addressed how it is often expected that camp is a place to experience one's (hetero)sexual firsts.

Aaron: Everyone at camp is open to their first. I think the girls think that way too. It's camp, this is where I met the first girl, I fell in love with at camp ... Camp changed my life in terms of girls. 


\section{NV STATI / ARTICLES}

So why at camp, and why not at home? We argue that this comes back to camp as a total institution; it is cut off from the real world, meaning that the consequences of being rejected or the potential stigma of being 'bad at it' are notably smaller than they would be at home. Did the campers who had same-gender sexual experiences also feel this way? Were they open to their sexual firsts too?

Jacob: Because we were so far away from them [the girls], there were things that would happen that would never happen, you know, like among my friend group back home. People just kind of brushed it off, you know, as fucking around ... that's why camp fucks with me because, now I am more comfortable with my sexuality, I like guys and girls, I think, like, was that my first sexual experience?

From the interviews, it appears that the sexual firsts were experienced by both same-gender and different-sex sexual encounters. However, it was the way in which they occurred and the meaning that was assigned to them that diffed. Even though the routines and rituals of most co-ed camps tend to favour heterosexual couples (who are mostly gender segregated for activities), instances of same-gender coupling did occur. Yet, they were often not understood as 'sexual firsts' in the same way they were for different-gender sexual interactions.

Outside our case study, many of the accounts in the media articles revealed camp to have this kind of effect. Camp was a place where campers tested the sexual waters. As the two quotes below show, there were many instances of same-gender exploration at camp, despite it being an institution with a strong heteronormative culture.

Article story: I sat in my cabin with another boy from my group, where we talked about ourselves and lives at home. After half an hour, he placed his hand on my upper thigh and said, 'Are you nervous?' I answered this question over and over again with a simple, 'No', as his hand continued to go higher. I did the same with him, experimenting and exploring his body. This was the first time I ever touched another boy - my first sinful encounter.

Blog story: It, like, was a whole summer thing, and I just remember being, like, I'm not gay so nothing's gonna happen and I would literally tell her to her face. I was, like, looking her in the eye and I was, like, I'm not gay. Aaand then it just happened one night.

Accounts like these were not uncommon in our data. Many described similar experiences while at camp. However, like Jacob's account, some experiences that 
people considered sexual when looking back on them, were not understood as sexual at the time.

Blog story: At ten, my friends and I would make out with hands covering our mouths.

Blog comment: It's where I really started to understand that I was 'different' than the other girls because we practised kissing too. But we didn't use our hands to cover our mouths. And this gave me many, many feelings.

Many of the straight campers interviewed recalled such experiences, but rather than these moments signifying the start of their queer experience, they simply explained them as 'it's camp'. 'It's camp' has some interesting connotations. We interpret this as a way of explaining that it is not 'real life' and acknowledging that the norms are different at camp. The straight campers (as well as many non-straight peers) discussed how same-gender intimate interactions are not something they would ever do at home. It is possible that this may simply be because they are away from their parents and family members. Yet, it was not framed this way in any of the interviews or in the media sources. It was attributed to the many ways in which camp was different from 'real life'. Though it appears that experiences of sexual firsts were similar for campers regardless of sexuality, only the not-straight former campers considered the same-gender sexual experiences to be sexual ones when looking back. This perhaps shows how pervasive the heterosexual norms of the culture at camp could be. As Jacob implied, the space at camp was different enough from home that it allowed (sexual) actions to occur that would not occur in the campers' friend groups at home. The heteronormative assumptions were strong enough that these actions could be interpreted by straight campers as 'just fucking around' because 'it's camp'. In contrast, for LGBTQ campers, sexual firsts led to sexual confusion, exploration, and awakening. Some LGBTQ campers later found it difficult to be sure whether certain actions, if they were sexual, 'counted' as a sexual first because of the covert way in which they occurred. These findings suggest that summer camps, as total institutions with institutionalised homosocial activities and culture, are formative sites where youth develop their sexual identity, learn sexual norms, and make sense of their sexual interactions.

\section{Out at camp}

We found strikingly differing narratives about whether to be out at camp. Navigating outness was an issue that most LBGTQ campers and counsellors faced while at summer camp. When looking back, many straight former campers acknowledged that camp was not a safe space in which to be out. 


\section{NV STATI / ARTICLES}

Abraham: It wasn't, like, terrible, camp just ... is maybe not the safest place to be out

When I asked Abraham more about this, he shared that he had many friends who came out in high school - he knew a handful in each grade - and his friends at other schools had similar levels of exposure to out classmates. However, at camp, he could not remember anyone being out and how camp seemed like a much harder place to be out compared to in 'real life.' Camp leadership seems to have significantly shaped how accepting (or intolerant) summer camps felt for queer campers. Instances of change in leadership demonstrate the extent to which tolerance was temporary and at the mercy of benevolent leaders.

Blog: I am out at camp. I will be returning this summer after taking off, and there's been a change in leadership. I'm terrified that it will no longer feel at home there because of my sexual orientation.

Campers often had to make decisions about whether to come out at camp. Many former campers recalled being conflicted about whether they felt safe to come out at camp, though most chose to hide their sexuality.

Blog: My problem is that I don't want to hide my sexuality from the girls in my cabin, but I worry because we shower/ swim/change in front of each other, and while I'm not going to be looking at any of them, I worry that they'll think I am. It seems easiest to hide it, but I don't think I can do that.

When faced with homophobic incidents at camp, others found it hard to reconcile their hidden sexual status.

Article: I heard one kid call another kid gay. I know how much that hurts. I wanted to reach out and say, 'Stand up and say that to me. Call me gay. Because I am gay'.

A lot of our data showed that the juxtaposition between the difficulty of being out at camp versus their love of camp was challenging for many campers and counsellors.

Blog: I remember feeling like camp - and my camp world - should have been the place more than any to give me solace and support during that difficult time in my life when I was coming out. The vivid memories of all the homophobic 
comments, jokes and pranks we played, however, negated any sense of safety this community had once given me.

Blog: Being out and gay at camp has always been a dream of mine.

Some chose to leave camp, as they could not reconcile the contrast in their head.

Blog: The only solution I could come up with was to disconnect from the only place where I had ever felt connected and to turn my back on those who had done so much to nurture my growth and grow my spirit. The sense of loss this created was overwhelming then and still leaves me feeling a little raw almost 20 years later.

Blog: The impact that this had on me was profound. Two years later when I was ready to come out I couldn't possibly fathom telling many of my friends from camp. Instead, I cut a huge swath of very important people from my life due to my fear of telling my former partners-in-homophobic-crime that I was gay.

Clearly, these accounts come from people who found something in the unique space at camp that made them want to stay in that environment. Often, camp was referred to as a summer home, as a place where they found belonging, as a place where they felt accepted. Coming out or the realisation that they were not straight coloured such perceptions greatly. Despite their love of camp, queer campers felt that camp was not a place where their sexuality would be accepted. The pain caused by the intolerant culture at camp was great for many former campers and counsellors alike. Though camp for many was a place they felt connection and belonging, as illustrated by the quotes above, LGBTQ campers' and counsellors' relationship with camp often soured due to a fear of how their sexuality/gender might be treated at camp.

Our second finding regarding being out at camp was about those who chose to be out at camp. It is important to note that some who came out had positive experiences.

Kayla: I think when I started getting to know the counsellors, that's when I started thinking about sexuality ... that was one of the first times I saw a gay relationship happen and it not matter.

Most of the younger participants could name three or four counsellors they knew who were out during their time at camp. One article also addressed a notable shift in acceptance of LGBTQ counsellors over time. However, our findings show that changes are not occurring everywhere. 


\section{NV STATI / ARTICLES}

The visibility of out counsellors did affect queer or questioning campers. Those that knew of out counsellors were more likely to come out during or shortly after camp. Research demonstrates that knowing other out persons or being in a space where there is visibility of queer persons makes the formation of a non-heterosexual identity easier (Rhoads 1997; Gray 2009; Wuest 2014). In the blogs, authors highlighted the impact that knowing out counsellors had on their self-concept about sexuality. A couple of blog posts echoed Kayla's sentiment:

Blog: For the first time in my life, I had proof that you could be a gay woman and be not only tolerated but liked. You could even be gay and weird and still be liked.

Blog: Word got around: some of the most beloved counsellors were definitely queer. The astonishing fact was that nobody cared.

These posts show how powerful visibility can be for queer youth; seeing people being out and others not caring had notable effects on self-acceptance. Many addressed it as a life-changing moment in how they viewed their own sexuality, and it was a pivotal moment in their own self-acceptance. However, for those at co-ed camps, counsellors' visibility did not protect them from rumours and microaggressions.

Benjamin: It was more just smirking, more just, you know, people, you know, talking about it, you know, rumours, nothing for sure, shit like that. It was more just like oh my God, like it's it, is she gay. Is she gay and I mean no one really spoke to her?

However, in our findings we found that Girl Scout camps uniquely had a strong and consistent effect of promoting lesbian visibility and acceptance. There were countless accounts and comments about Girl Scout camps being uniquely queerfriendly spaces and the first time that queer campers had witnessed the acceptance of queer role models.

Blog: Our counsellors were strong women, very much comfortable with who they were, and fearless.

Blog comment: Counsellors with dreadlocks and shaved heads and, sometimes, relationships with each other.

There were even some instances of counsellors themselves, both at Girl Scout and other camps, realising at camp that they were not straight. 
Blog comment: At least half of the queer counsellors didn't come out or even really consider that they were queer until they came to camp. I've worked at camps for five summers, during all of which I've known people who would previously have identified as straight start dating other counsellors.

In our case study, in almost everyone's recollection, there were no out campers, though some of our participants identified as queer and some were out at camp. Those who were out, were not out to their whole camp community but to a few selected confidants. It is important to note the low level of disclosure even among those who recalled being out at camp. They expressed only being out to the people in their group and some counsellors. Participants explained how camp was not the safest or best place to come out. The girls explained that camp was very heteronormative and intimate in shared spaces so girls might not feel comfortable breaking this norm. The boys described the overtly masculine environment that teen house culture creates and the presence there of gay slurs and homophobic language. The lack of visibility and acceptance is deeply problematic. It has a ripple effect that makes the space feel unsafe for both camp staff and campers. However, when there are visible LGBTQ role models, campers have a space in which to explore their sexuality, or at least consider it, with less fear of judgment, stigma, or internalised shame.

\section{Discussion and conclusion}

For questioning or presently LGBTQ-identified campers, camp was a place where they tested the sexual waters. For many, this was often their first sexual encounter, same-gender or otherwise. They were acting upon intuition, desires, and impulses in the moment. Most campers, straight or otherwise, attributed their sexual 'firsts' at camp to their being more confident or being a different person at camp. They found freedom in being away from 'real life'. Nevertheless, straight and LGBTQ participants constructed same-gender firsts differently. There are distinct differences between these identities that lead to divergent framings of their experiences. Whereas straight campers continued to interpret same-gender encounters from camp as innocuous preparation for 'real' sex acts, LGBTQ campers re-interpreted similar experiences as the ones that helped them discover their LGBTQ identity. The occurrence of non-normative sex acts at camp, then, contradicts the allegedly chaste and restrained nature of camp, but does not undo the compulsory heterosexuality that is structurally embedded in it.

One of the biggest contentions in our findings was why some campers and counsellors chose to come out, while the majority chose to hide their sexuality? For many campers, the act of coming out or realising that they were not straight was 


\section{NV STATI / ARTICLES}

difficult, especially in the context of camp; they were aware that camp might not be a place where their sexuality would be accepted. Campers, in addition to coming to terms with their sexuality, had to contend with the fact that a place they loved was also a place that was defined by microaggressions and heteronormative structures. The pain caused by this duality of experiences was palpable for many former campers and counsellors alike.

Our findings show that the visibility of older counsellors or campers who were 'out' created an environment where campers could safely explore their sexuality and come out. The coming out process happens in stages, and visible role models help young people in their sexual development and help them to develop a queer consciousness and self-acceptance (Rhoads 1994; Horowitz, Newcomb 2002). Our findings show that the visibility of other LGBTQ people was a key factor in influencing how campers came to terms with their sexuality, and when visibility was present and positive, that visibility became a pivotal moment for their own self-acceptance. Despite widespread fear, we did not come across instances of negative consequences of coming out among former campers. Further research is needed to determine how often campers come out at camp and the reception by the camp community. Those at camps with stronger heteronormative messaging and no LGBTQ visibility were less likely to even take the risk of coming out. It may be that the binaristic framework of being 'out' is problematic, as coming out is an ongoing process (De Monteflores, Schultz 1978). Some participants talked of being out to only a few people at camp, and so were not out to the wider camp population.

As researchers have found in other heteronormative institutions, an unwelcoming environment for LGBTQ people is created by the strong emphasis on heteronormative behaviours, gender segregation that depicts young boys and girls as sexual opposites, and the ritualised ridiculing of homosexuality (Milner, Braddock 2016; Harvey 2017; Devís-Devís et al. 2018). The fear or suspicion of it not being safe to be out was not just felt among the LGBTQ campers and counsellors; upon reflection, the straight campers also explicitly stated they did not think it would be safe to be out at camp. In addition, many of our interviewees were still in the early stages of realising their sexuality when they were at camp. They may not yet have been in a position even to fully accept, understand, or acknowledge their identity. As many campers are in the early stages of developing their sexuality, this might also explain the lack of outness. What this does not account for, however, is the lack of out counsellors, and the frequent acknowledgement from participants that camp did not feel like a safe space to be out. Our findings demonstrate a strong culture within this institution that indicates it to be a 'straights only' space, where the consequence of being out may include inescapable ridicule, exclusion, and bullying. Other closeted campers and counsellors felt that they could not return to camp. 
Relegating the non-straight non-cis counsellors to being in charge of only younger campers demonstrates that they were not seen as equals to other counsellors and were perhaps viewed as a threat to adolescents, the thereby systematically weakening the authority and respect that the LGBTQ counsellors received. The discriminatory practices at camp contributed to why many campers felt that it was not a safe space for non-normative gender and sexuality. Like other institutions, camp is set up as a performative heterosexual space (Bell et al. 1994; Valentine 1996). This heteronormativity affects not only institutional practices but, as we found in our research, also the ways in which young campers make sense of their everyday behaviours. Among the campers in our study, same-gender sex acts were interpreted as 'practising their heterosexuality' on same-gender partners before going out and enacting 'the real thing,' and same-gender homoerotic interactions could occur in plain sight under the guise of 'fucking around'. The rules and rituals of the institution as described in this article demonstrate how the provision of heterosexual spaces continues the maintenance of heteronormative expectations of the status quo (Butler 1990). Therefore, our findings show that camp systems fail to ensure same-gender interactions are seen as valid and legitimate and they are instead seen as something that should be ridiculed.

Despite their love for camp, many campers chose to disconnect from or leave the camp community altogether. The heteronormative culture at camp often pushed LGBTQ members to choose between two undesirable options: staying in the closet or exiting the camp community. To stay at camp means to stay in the closet, and that leads to identity erasure at camp, a community that offers simultaneously a sense of belonging and exclusion. Conversely, leaving the camp community becomes a form of self-exile, where one loses access to the networks and institutions that provide crucial support and acceptance for many youths. Because summer camps are total institutions, they exert undue influence on the structure of camp activities and its cultural norms. Through its disconnection from 'real life' camp provides a uniquely unencumbered environment for teenagers to form bonds and discover themselves, those who fall outside its cultural norms experience stigma and become excluded. As a voluntary institution, summer camp allows campers the opportunity of stepping out of 'real life', forming bonds, and recreating themselves, all of which can provide comfort for countless youth. Yet, this total institution is situated in the context of the real world in which the norms of heterosexuality and cis-gender identity operate as powerful social forces. Unfortunately, most camps have failed to leave behind hegemonic norms around gender and sexuality. The confined and removed nature of this space means in most cases that the perceived consequences or risks associated with non-normative behaviours are exacerbated. Community support is an essential part of the coming out process, yet LGBTQ campers and counsellors lose access to 


\section{NV STATI / ARTICLES}

this core network of peers and mentors (Herek, Glunt 1993; Gaines, Garand 2010). In this way, camps not only exclude LGBTQ members of their community but also contribute to the stigmatisation and ostracisation of non-normative members.

We must consider these parallel feelings, that juxtaposition, many experience at camp: safe in some ways and yet not safe at the same time. Since campers have a love of camp, how do the categories, identities, and forms of activism that exist in one context (outside camp) not always translate to another context (at camp)? Why are camps not working harder to be a space for greater inclusion? Is there a need for camp affinity spaces for LGBTQ campers and counsellors alike? Moreover, as we see a growing adult camp industry that demonstrates the significance of camp for many that extends beyond their youth, people are looking to replicate their camp experience. These last questions remain: can camp be queered? Can camp become an inclusive and safe space for queer youth, or do we need to continue growing and utilising separate LGBTQ summer camps? We argue that though it is important to have LGBTQ spaces (see nightclubs) that provide a vital experience of community and bonding for LGBTQ youth and adults, it is equally important to ensure that traditional camps are just as safe and welcoming for LGBTQ campers, especially as LGBTQ campers often have not yet fully formed these identities yet, may not have the resources to go to separate camps, may not have family support to exist in these spaces, and deserve to have access to the same spaces as their peers.

Camps must ensure that people who may want to be out can be certain that there will be no negative consequences from their choice to disclose. The American Camp Association only recently provided guidance for ensuring the safety and acceptance of LGBTQ campers at camp. Many camps have 'at-will' employment, meaning even with federal protections, it is easy to be fired with little recourse. Provisions for LGBTQ campers and counsellors are not part of the criteria for official accreditation, regulations, or rankings for summer camps. We recommend the ACA create additional guidelines and required leadership training for accreditation that ensures exposure to diverse sexuality and gender issues and provisions. Camps happen during pride month. Having age-appropriate pride celebrations would be a clear way camps could signal a culture of inclusion and acceptance. Big camp events fit well with the norms of pride (costumes, floats, parades) and would be a major indication of growth in cis/ heteronormative spaces. Though small change is happening over time, regulatory camp bodies and individual camp policies must do more to ensure that camps are anti-homophobic and a safe space for everyone who attends them.

Just as the total institution of summer camp has institutionalised heteronormativity, it is responsible for creating both top-down and bottom-up cultural norms that lead to the acceptance of LGBTQ members. They can do this through LGBTQ visibility and a culture of embracing non-normative behaviours. The contact hypothesis shows 
us that contact with LGBTQ people increases acceptance for LGBTQ people, and the strength and depth of that contact increases its effects. Camp is a place where longstanding, deep, and meaningful bonds are created, so the visibility of LGBTQ counsellors is essential for those who are developing their sexual identity. Space for non-straight sexuality development needs to exist as much as it currently does for straight campers. Notably, straight sexual firsts are supported by the institution's rituals, whereas same-gender identities and desires are delegitimised by the institution. In our case study, we observed the institutionalisation of rituals associated with hegemonic masculinity, a practice that cements the sexual objectification of women and the delegitimisation of same-gender desire (Connell, Messerschmidt 2005). Part of the heteronormative nature of the institution is its entrenched mirroring of hegemonically masculine values. Recent studies have explored how (primarily cisgender and straight) men do and make meaning out of (homo)social and (hetero)sexual behaviour in gender-segregated settings, such as bars, fraternities, and workplaces (Higate 2012; Wadham 2013; 2017; McCloskey 2020; Crowhurst,Eldridge 2020). Early studies on masculinity and sexuality emphasised hegemonic masculinity's rigid norms and status hierarchy over subordinate masculinities and women (Connell 1987). Empirical studies note that stereotypically 'masculine' qualities, such as being aggressive, competitive, or hypersexual, are performed in clear distinction from alternative masculinities (Bird 1996; Britton 1990). Theorists have made interventions to problematise essentialist perspectives on masculinity and have instead emphasised the relational nature of hegemonic masculinity, which is historically and locally situated (Connell 1995; Connell and Messerschmidt 2005). Our data, from interviews and media sources, suggest that hegemonic masculinity is relational and fluid, rather than absolute and fixed. The development and embodiment of hybrid masculinities, at camp and beyond, is an area for future research. We find that understanding how hegemonic masculinity functions both relationally and hierarchically helps provide a framework for how sexuality functions at camp. Camp as an institution supports hegemonic ideals of masculinity, straightness becomes the default through its structures and rituals, and boys are expected to be dominant (Harvey 2017). Given its distance from 'real life,' however, the social consequences of defying gender and sexual norms are diminished to the extent that non-normative behaviours, such as same-gender exploration, take place. Therefore, camp becomes a paradoxical space where the institutionalisation of heteronormativity and non-normative behaviours coexist.

This research addresses the unique circumstances of summer camp, a locale where youth sexuality development takes place under the auspices of a total institution. Even though summer camps remain a prominent aspect of childhood and young adulthood in the United States, there exists limited research on them, especially regarding how they shape gender and sexual identity development. This study combines multiple 


\section{NV STATI / ARTICLES}

data sources - interviews from a case study and online media sources, including podcasts and blogs - to explore the ways in which heteronormativity defines camp structure and culture. We find that the context of summer camps, as total institutions, uniquely shapes how campers imagine sexual encounters. This was especially the case with same-gender sex acts. Not only did camp create the optimal setting for sexual firsts, but it also allowed campers, regardless of sexual orientation, to engage in non-normative sexual behaviours without challenging heteronormativity. While non-normative behaviours often took place in the shadows, being publicly out remained challenging, both for campers and counsellors. These findings reaffirm the idea that normative institutions and non-normative behaviours often coexist, as demonstrated in the context of childhood sexuality in this study. Specific locales give rise to cultural norms that might simultaneously discourage certain behaviours and allow them to flourish if justifiable under the cultural norms. This study, then, should be understood as contributing to newly emerging strands of research on childhood sexuality, childhood institutions, and queer sexual development that seek to better understand how LGBTQ youth develop their sexuality through interactions with institutions, role models, and peers.

Perhaps with the exception of Girl Scout camps, the institution of camp remains a cis-heteronormative institution, both in structure (segregated spaces based upon gender) and ritual (couples walks and prom). Camp activities and structures implicitly encourage campers to pair up and experiment with the 'opposite gender'. The institution's anxieties around cross-gender interactions (and presumed sexual goingson between boys and girls) lead to the structure of camp - both as an institution and its daily activities - to be shaped around the separation of genders. However, we find that campers are more likely to have sexual firsts, including with a samegender partner, at camp than they are at home, despite camp's gender-segregated spaces. More work needs to be done to change heteronormative culture and rituals at summer camps. Yet, with the education of camp directors and other leadership, requirements from the American Camp Association, and the development of an openly inclusive environment, we believe that changes can occur. We advocate for the de-gendering of spaces at camp and for all genders to be mixed, hopefully limiting some of the effects of the assumption of heterosexuality. Moreover, LGBTQ counsellors should not be required to hide their identities; rather, they should be celebrated as role models by the institutions to demonstrate and model acceptance. If done well, camps can become safe spaces for non-straight, non-cis campers. Camp should be a place where all members feel safe, validated, and welcome. Camps need to do more to ensure that the environment is accepting of all people, regardless of their sexuality. 


\section{References}

ACA Camp Compensation and Benefits Report. 2010. 'ACA Facts and Trends.' American Camp Association. Retrieved 4/28/2015 (http://www.acacamps.org/media/aca-factstrends).

Bargiela-Chiappini, F. 2007. Liminal Ethnography: Understanding Segregated Organisations. Qualitative Research in Organizations and Management: An International Journal 2 (2): 126-143, https://doi.org/10.1108/17465640710778520.

Braun, V., V. Clarke. 2006. Using Thematic Analysis in Psychology. Qualitative Research in Psychology 3 (2), 77-101, https://doi.org/10.1191/1478088706qp063oa.

Baker, M., J. Hannant-Minchel. 2020. 'Both Are Equal, Which Is Awesome': Exploring Gendered Discourses of Canadian Summer Camp Experiences. Annals of Leisure Research: 1-18, https://doi.org/10.1080/11745398.2020.1848596.

Bell, D., J. Binnie, J. Cream, G. Valentine. 1994. All Hyped Up and No Place to Go. Gender, Place and Culture: A Journal of Feminist Geography 1 (1): 31-47, https://doi. org/10.1080/09663699408721199.

Browne, L. P., A. Gillard, B. A. Garst. 2019. Camp as an Institution of Socialization: Past, Present, and Future. Journal of Experiential Education 42 (1): 51-64, https://doi. org/10.1177/1053825918820369.

Brown-Saracino, J. 2015. How Places Shape Identity: The Origins of Distinctive LBQ Identities in Four Small US Cities. American Journal of Sociology 121 (1): 1-63, https:// doi.org/10.1086/682066.

Butler, J. 1990. Gender Trouble, Feminist Theory, and Psychoanalytic Discourse. Pp. 324340 in Nicholson, L. J. (ed.). Feminism/Postmodernism. New York: Routledge.

Connell, R. W., J. W. Messerschmidt. 2005. Hegemonic Masculinity: Rethinking the Concept. Gender \& Society 19 (6): 829-859, https://doi.org/10.1177/0891243205278639.

Cookson, P. W., C. H. Persell. 1985. Preparing for Power: America's Elite Boarding Schools. New York City: Basic Books.

Coleman, E. 1982. Developmental Stages of the Coming Out Process. Journal of Homosexuality 7 (2-3): 31-43, https://doi.org/10.1300/J082v11n01_08.

Coleman, E. 1985. Bisexual Women in Marriages. Journal of Homosexuality 11 (1-2): 87100.

Costa, P. A., H. Pereira, I. Leal. 2015. 'The Contact Hypothesis' and Attitudes toward Same-Sex Parenting. Sexuality Research and Social Policy 12 (2): 125-136, https://doi. org/10.1007/s13178-014-0171-8.

Cox, S., D. S. Bimbi, J. T. Parsons. 2013. Examination of Social Contact on Binegativity among Lesbians and Gay Men. Journal of Bisexuality 13 (2): 215-228, https://doi.org/10.1 080/15299716.2013.782596.

Crowhurst, I., A. Eldridge. 2020. 'A Cathartic Moment in a Man's Life': Homosociality and Gendered Fun on the Puttan Tour. Men and Masculinities 23 (1): 170-193, https://doi. org/10.1177/1097184X18766578.

Davies, C. 1989. Goffman's Concept of the Total Institution: Criticisms and Revisions. Human Studies 12 (1): 77-95, https://www.jstor.org/stable/20009046. 


\section{NV STATI / ARTICLES}

Davis-Delano, L. R., A. Gillard. 2015. Summer Camp as Context for Girls' and Women's Same-Sex Attractions and Relationships. Leisure/Loisir 39 (1): 1-36, https://doi.org/10.108 0/14927713.2015.1074400.

Devís-Devís, J., S. Pereira-García, E. López-Cañada, V. Pérez-Samaniego, J. Fuentes-Miguel. 2018. Looking Back into Trans Persons' Experiences in Heteronormative Secondary Physical Education Contexts. Physical Education and Sport Pedagogy 23 (1): 103-116, https://doi.org/10.1080/17408989.2017.1341477.

De Monteflores, C., S. J. Schultz. 1978. Coming Out: Similarities and Differences for Lesbians and Gay Men. Journal of Social Issues 34 (3): 59-72, https://doi. org/10.1111/j.1540-4560.1978.tb02614.x.

Garner, A. 2013. Ambivalence, the Intergroup Contact Hypothesis, and Attitudes about Gay Rights. Politics \& Policy 41 (2): 241-266, https://doi.org/10.1111/polp.12010.

Gaines, N. S., J. C. Garand. 2010. Morality, Equality, or Locality: Analyzing the Determinants of Support for Same-Sex Marriage. Political Research Quarterly 63 (3): 553-567, https:// doi.org/10.1177/1065912909333132.

Ghaziani, A. 2015. 'Gay Enclaves Face Prospect of Being Passé': How Assimilation Affects the Spatial Expressions of Sexuality in the United States. International Journal of Urban and Regional Research 39 (4): 756-771, https://doi.org/10.1111/1468-2427.12209.

Goffman, E. 1968. Asylums: Essays on the Social Situation of Mental Patients and Other Inmates. Piscataway, NJ: Aldine Transaction.

Gray, M. L. 2009. Out in the Country: Youth, Media, and Queer Visibility in Rural America. New York: NYU Press.

Grace, J. 1979. Coming Out Alive: A Positive Developmental Model of Homosexual Competence. Paper presented at the Sixth National Association of Social Workers Professional Symposium, Social Work Practice: Directions for the 1980s, San Antonio, Texas, November.

Gillard, A., E. E. Buzuvis, M. D. Bialeschki. 2014. Supporting Transgender and Gender Nonconforming Youth at Summer Camp. Journal of Park \& Recreation Administration 32 (3): 92-105.

Griffith, K. H., M. R. Hebl. 2002. The Disclosure Dilemma for Gay Men and Lesbians: 'Coming Out' at Work. Journal of Applied Psychology, 87 (6) 1191, https://doi. org/10.1037/0021-9010.87.6.1191.

Harvey, P. 2017. 'It's Camp': Summer Camp Culture, the Renegotiation of Social Norms and Regulation of Gender and Sexuality. Master's thesis, Department of Sociology, Georgia State University. Scholarworks. Retrieved 22/11/2021 (https://scholarworks.gsu.edu/ sociology_theses/70).

Higate, P. 2012. Drinking Vodka from the 'Butt-Crack': Men, Masculinities and Fratriarchy in the Private Militarized Security Company. International Feminist Journal of Politics 14 (4): 450-469, https://doi.org/10.1080/14616742.2012.726092.

Herek, G. M., E. K. Glunt. 1993. Interpersonal Contact and Heterosexuals' Attitudes toward Gay Men: Results from a National Survey. Journal of Sex Research 30 (3): 239-244, https://doi.org/10.1080/00224499309551707.

Horowitz, J. L., Newcomb, M. D. 2002. A Multidimensional Approach to Homosexual 
Identity. Journal of Homosexuality 42 (2): 1-19, https://doi.org/10.1300/J082v42n02_01. Julian, N., D. K. Duys, S. M. Wood. 2014. Sexual Identity Formation of Women Who Love Women: A Contextual Viewpoint. Journal of LGBT Issues in Counselling 8 (2): 189-205, https://doi.org/10.1080/15538605.2014.895665.

Kar, S. K., A. Choudhury, A. P. Singh. 2015. Understanding Normal Development of Adolescent Sexuality: A Bumpy Ride. Journal of Human Reproductive Sciences 8 (2): 70-74, https://doi.org/10.4103/0974-1208.158594.

Kazyak, E. 2012. Midwest or Lesbian? Gender, Rurality, and Sexuality. Gender \& Society 26 (6): 825-848, https://doi.org/10.1177/0891243212458361.

Khan, S. R. 2012. Privilege: The Making of an Adolescent Elite at St. Paul's School. Princeton, NJ: Princeton University Press, https://www.jstor.org/stable/j.ctt7s88z. Kidd, K. B., D. Mason, K. Eveleth, K. Kent, D. Gilson. 2019. Queer as Camp: Essays on Summer, Style, and Sexuality. New York: Fordham University Press, https://doi. org/10.2307/j.ctvfjd074.

Kinsey, A. C., W. B. Pomeroy, C. E. Martin. 1949. Sexual Behaviour in the Human Male. The Journal of Nervous and Mental Disease 109 (3): 283.

McCloskey, D. 2020. Brothers as Men: Masculinity, Homosociality, and Violence among Fraternity Men. Doctoral dissertation, University of Connecticut.

Milner, A. N., J. H. Braddock II. 2016. Sex Segregation in Sports: Why Separate Is Not Equal: Why Separate Is Not Equal. Santa Barbara, CA: ABC-CLIO.

Nenga, S. K., T. P. Baccam. 2010. Stealing Peanuts and Coercing Energy Drinks: The Underground Economy of a Middle School Summer Camp. Qualitative Sociology Review $6(2):$ 105-125.

Oakleaf, L. 2010. Managing Identity: The Experience of Residential Summer Camp Staff Who Self-Identify as Lesbian, Gay, Bisexual, or Transgender. Doctoral Dissertation, North Carolina State University.

Peterson, L. W. 2015. The Art of Being Straight. Journal of Bisexuality 15 (2): 295-297, https://doi.org/10.1080/15299716.2015.1033918.

Ragins, B. R., R. Singh, J. M. Cornwell. 2007. Making the Invisible Visible: Fear and Disclosure of Sexual Orientation at Work. Journal of Applied Psychology 92 (4): 11031118.

Rhoads, R. A. 1994. Coming Out in College: The Struggle for a Queer Identity. Westport, CT: Greenwood Publishing Group.

Rhoads, R. A. 1997. Implications of the Growing Visibility of Gay and Bisexual Male Students on Campus. NASPA Journal 34 (4): 275-286, https://doi.org/10.2202/19496605.1029.

Schaverien, J. 2004. Boarding School: The Trauma of the 'Privileged' Child. Journal of Analytical Psychology 49 (5): 683-705, https://doi.org/10.1111/j.00218774.2004.00495.x.

Valentine, G. 2000. Introduction: From Nowhere to Everywhere: Lesbian Geographies. Journal of Lesbian Studies 4 (1): 1-9, https://doi.org/10.1300/J155v04n01_01.

Van Slyck, A. 2006. A Manufactured Wilderness: Summer Camps and the Shaping of American Youth 1890-1960. Minneapolis, MN: University of Minnesota Press. 
Vrooman, P. D. 2007. Passing Masculinities at Boy Scout Camp. Doctoral dissertation, Bowling Green State University. Retrieved 22/11/2021 (http://rave.ohiolink.edu/etdc/ view?acc_num=bgsu1182780149).

Ward, J. 2008. Dude-Sex: White Masculinities and 'Authentic' Heterosexuality among Dudes Who Have Sex with Dudes. Sexualities 11 (4): 414-434, https://doi. org/10.1177/1363460708091742.

Wadham, B. 2013. Brotherhood: Homosociality, Totality and Military Subjectivity. Australian Feminist Studies 28 (76): 212-235, https://doi.org/10.1080/08164649.2013.792440.

Wadham, B. 2017. Violence in the Military and Relations among Men: Military Masculinities and 'Rape Prone Cultures'. Pp. 241-256 in The Palgrave International Handbook of Gender and the Military. Palgrave Macmillan, London, https://doi.org/10.1057/978-1137-51677-0_15.

Wuest, B. 2014. Stories like Mine: Coming Out Videos and Queer Identities on YouTube. Pp.19-33 in Queer Youth and Media Cultures. London: Palgrave Macmillan, https://doi.org/10.1057/9781137383556_2.

(c) BY-NC Penny Harvey, Juhwan Seo, Emily Logan, 2021.

(c) BY-NC Institute of Sociology of the Czech Academy of Sciences, 2021.

Penny Harvey is an Assistant Professor of Human Sexuality Studies at the California Institute for Integral Studies. They work at the intersections of gender, sexualities, health, culture, and identity. Contact e-mail: Pharvey@ciis.edu.

Juhwan Seo is a PhD Candidate in Sociology at Cornell University. He studies how US immigration policy shapes family formation of queer immigrants. Contact e-mail: js2583@cornell.edu.

Emily Logan is an independent research and graduate of Sociology at Georgia State University. Contact e-mail: eclairelogan@gmail.com. 